\title{
Circadian rhythms in the three-dimensional genome: implications of chromatin interactions for cyclic transcription
}

\author{
Ignacio Pacheco-Bernal ${ }^{\dagger}$, Fernando Becerril-Pérez $^{\dagger}$ and Lorena Aguilar-Arnal ${ }^{*}$ [D
}

\begin{abstract}
Circadian rhythms orchestrate crucial physiological functions and behavioral aspects around a day in almost all living forms. The circadian clock is a time tracking system that permits organisms to predict and anticipate periodic environmental fluctuations. The circadian system is hierarchically organized, and a master pacemaker located in the brain synchronizes subsidiary clocks in the rest of the organism. Adequate synchrony between central and peripheral clocks ensures fitness and potentiates a healthy state. Conversely, disruption of circadian rhythmicity is associated with metabolic diseases, psychiatric disorders, or cancer, amongst other pathologies. Remarkably, the molecular machinery directing circadian rhythms consists of an intricate network of feedback loops in transcription and translation which impose 24-h cycles in gene expression across all tissues. Interestingly, the molecular clock collaborates with multitude of epigenetic remodelers to fine tune transcriptional rhythms in a tissue-specific manner. Very exciting research demonstrate that three-dimensional properties of the genome have a regulatory role on circadian transcriptional rhythmicity, from bacteria to mammals. Unexpectedly, highly dynamic long-range chromatin interactions have been revealed during the circadian cycle in mammalian cells, where thousands of regulatory elements physically interact with promoter regions every $24 \mathrm{~h}$. Molecular mechanisms directing circadian dynamics on chromatin folding are emerging, and the coordinated action between the core clock and epigenetic remodelers appears to be essential for these movements. These evidences reveal a critical epigenetic regulatory layer for circadian rhythms and pave the way to uncover molecular mechanisms triggering pathological states associated to circadian misalignment.
\end{abstract}

Keywords: Environmental epigenetics, Circadian clocks, Chromatin, Genome topology, Transcription

\section{Background}

Circadian rhythms are apparent in most living organisms, as persistent 24-h cycles in physiology, behavior, or even metabolism. They have evolved to adapt and anticipate daily environmental fluctuations, temporally segregating biological functions to specific hours along the day. For example, in humans, sleep/wake cycles are under circadian control, and they fluctuate in coherence with feeding/fasting periods. As a result, metabolic fluxes show rhythmic regulation in most tissues, allowing the organisms to efficiently couple food intake with

\footnotetext{
* Correspondence: loreaguilararnal@iibiomedicas.unam.mx

${ }^{\dagger}$ Ignacio Pacheco-Bernal and Fernando Becerril-Pérez contributed equally to the work.

Instituto de Investigaciones Biomédicas, Departamento de Biología Celular y Fisiología, Universidad Nacional Autónoma de México, Mexico City, Mexico
}

adequate energy use [1]. Moreover, cognitive functions, such as learning or memory formation, are clock controlled, and circadian synaptic plasticity has been evidenced [2]. Hence, circadian control of physiology has broad implications, which manifest when the circadian clock is disrupted, leading to disease. For example, genetic or pharmacological perturbations of circadian rhythms can lead to obesity and type 2 diabetes and, remarkably, disruption of light/dark cycles or arbitrary feeding schedules are strongly associated with metabolic disorders [3]. Indeed, other pathological conditions including cardiovascular diseases, inflammation, cancer, or psychiatric disorders are also related to circadian misalignment [4]. Indeed, uncovering the rules governing circadian rhythms can pave the way to prevent and treat complex diseases prevalent in modern societies.

(c) The Author(s). 2019 Open Access This article is distributed under the terms of the Creative Commons Attribution 4.0 International License (http://creativecommons.org/licenses/by/4.0/), which permits unrestricted use, distribution, and 
Classic and novel genetic and molecular biology approaches shed light on the gears of circadian rhythms at the cellular level [5]. Remarkably, the molecular components of the circadian clock are a combination of transcriptional activators and repressors coordinately acting at thousands of sites in the chromatin fiber and ultimately driving a highly specific program of gene expression around the day $[5,6]$. Within each tissue, distinct genetic networks are controlled by the molecular clock, through synchronized action with tissue-specific transcription factors and epigenetic remodelers [7-9]. Complex regulatory networks intertwine to modulate the circadian clock, providing means to adapt the circadian program of gene expression to environmental signaling. In this scenario, chromatin dynamics plays a pivotal role on clock-controlled transcription, and it is conceptually apparent that organizational principles of the genome within the nuclear space contribute to rhythmic transcription, as it has been demonstrated in latest research. In this review, we will discuss findings uncovering the implications of epigenetic regulation genome folding on circadian clock function, with special emphasis on evidences relating three-dimensional properties of chromatin to cyclic transcription.

\section{The mammalian circadian clock}

In mammals, the circadian clock is a time tracking system that allows the organism to anticipate and adapt to environmental changes. This system is organized as a hierarchy of oscillators, coordinated by a central pacemaker located in suprachiasmatic nucleus $(\mathrm{SCN})$ of the hypothalamus. The SCN is composed of about 20,000 neurons with unique network properties that confer the entire nucleus a remarkable synchrony in its electrical properties, showing autonomous circadian cycles in the action-potential firing from these pacemaker neurons [10]. Remarkably, the SCN is enough to drive circadian behavior, and participates in the control of circadian physiology. Although it generates endogenous and self-sustained rhythms, the SCN must receive external cues to daily synchronize with the environment and keep the correct time. Interestingly, the $\mathrm{SCN}$ receives light information directly form a subset of retinal ganglion cells expressing the specific photopigment melanopsin, through the retinohypothalamic tract [11]. Blue light is therefore the strongest time giver in most of mammalian species, as it entrains the central pacemaker to keep it on time. However, subsidiary clocks in the rest of the body, which are not sensitive to photic entrainment, must be also synchronized. This is partially achieved by signaling from the $\mathrm{SCN}$ through the coordinated action of humoral, hormonal, and neural inputs into peripheral clocks, located at other areas of the brain and distinct tissues [11]. Additionally, certain environmental cues, such as food intake, temperature, exercise, and drug exposure, can synchronize peripheral clocks to reinforce the alignment between them or, on the contrary, disturb this synchrony when exposure is unfavorable, a case that can lead to disease [12]. Some of the pathologies driven by circadian misalignment are cardiovascular diseases, obesity and metabolic syndrome, mental disorders, or even cancer [12].

At the cellular level, a circadian molecular machinery coordinates rhythmicity by autoregulatory feedback loops in transcription and translation. Interestingly, the core components of this molecular gear are transcription factors which timely regulate their own synthesis and degradation in 24-h cycles. In mammals, the positive limb of the loop is driven by two b-HLH (b-helix-loop-helix) PER-ARNT-SIM (bHLH-PAS) domain proteins, CLOCK (Circadian Locomotor Output Cycles Kaput) and BMAL1 (Brain and Muscle ARNT-Like Protein-1), which heterodimerize and bind to the consensus motif e-box in the genome (Fig. 1a). CLOCK:BMAL1 recruitment to chromatin triggers nucleosome remodeling and primes genes for PolII-mediated transcriptional activation [13, 14]. Some of the genes activated by CLOCK:BMAL1 heterodimers are Period (Per1-3) and Cryptochromes (Cry1-2) genes, which when translated, dimerize together and with members of the casein kinase 1 family $(C K 1 \alpha, C K 1 \varepsilon)$ and conform the Period repressive complexes $[15,16]$. Notably, Period complexes are subjected to multiple posttranslational modifications, such as phosphorylation, ubiquitylation, or acetylation, which modulate its activity $[16,17]$. Period complexes translocate into the nucleus to displace CLOCK:BMAL1 from chromatin, hence transcriptionally silencing Per and Cry genes (Fig. 1a). Remarkably, Period complexes have very tightly controlled half-lives through specific E2-Ubiquitin ligases, which target them for proteasomal degradation. Clearance of period complexes releases CLOCK:BMAL1 activators which subsequently can reenter another cycle of transcriptional activation. Through this mechanism, a significant set of genes are expressed in 24-h cycles, corresponding to the length of the transcriptional-translational feedback loop [18].

Additional to the core clock TTFL, several regulatory loops interlock. For example, expression of the nuclear receptors (NRs) Nr1d1 and Nr1d2 (also known as $R E V-E R B \alpha$ and $R E V-E R B \beta)$ is activated by CLOCK:BMAL1 (Fig. 1a). These NRs are transcriptional repressors that bind to the RevDR2 and retinoic acid-related orphan receptor (ROR)-binding elements (ROREs), which are also recognized by the ROR family of NRs, ROR $\alpha$, ROR $\beta$, and ROR $\gamma$. This molecular crosstalk controls rhythmic Bmal1 and Cry1 expression, evidencing a specific circadian cistrome coordinating cyclic 


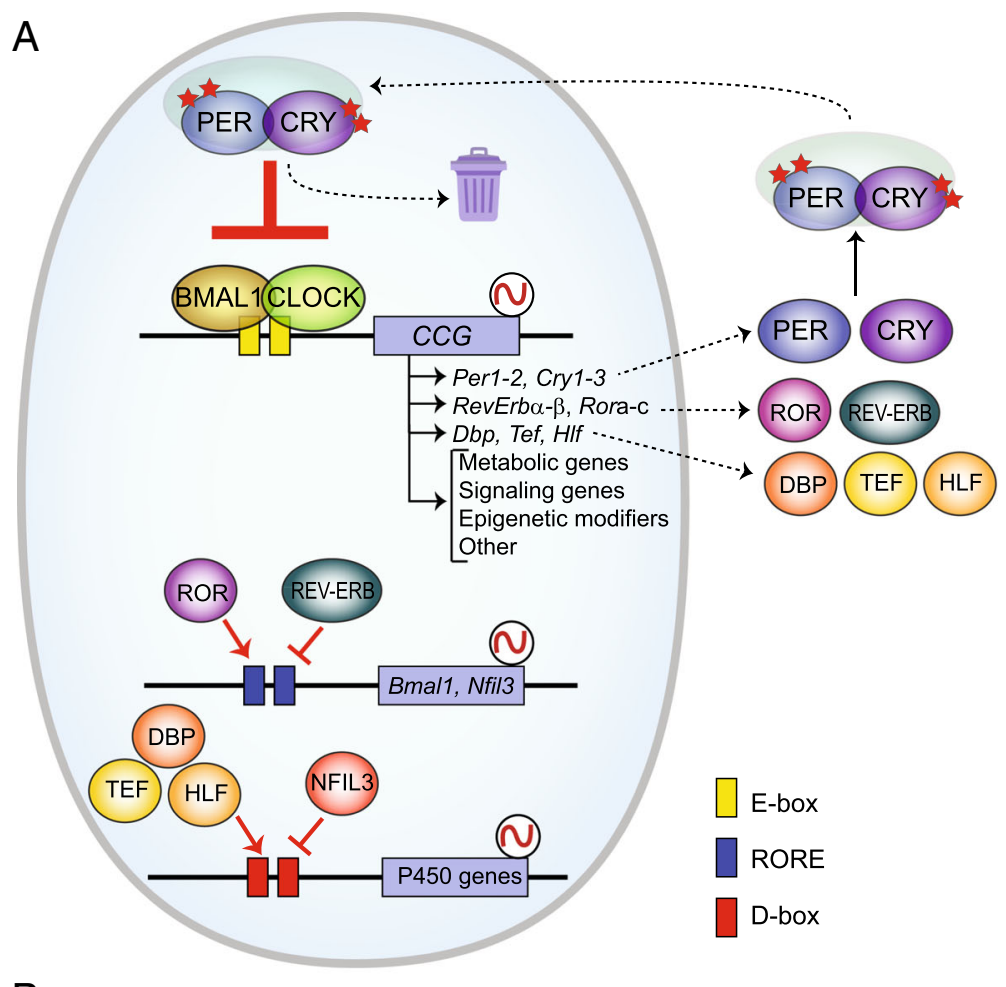

B

Regulatory epigenetic layers:

-Interphasic nuclear organization

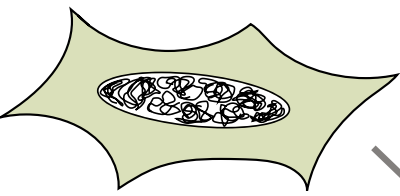

-Chromatin modifications

MLL1 Jarid1a

EZH2 SIRT1

CBP-p300

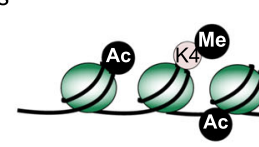

$\begin{array}{cl}\text {-Specific transcription } \\ \text { factors } \\ \text { HNF4 } & \text { NFKB } \\ \text { GR } & \text { FOXO1 }\end{array}$



Fig. 1 The mammalian circadian clock. a Schematic representation of the molecular clock. The transcriptional activators CLOCK:BMAL1 rhythmically bind to E-boxes (yellow rectangles) and activate expression of clock-controlled genes (CCG). Amongst these CCG, the circadian repressors Cry $1-2$ and Per1-3 are transcribed. Upon translation, Period complexes are ensembled in the cytoplasm, and distinct posttranslational modifications control its activity (red stars). Nuclear translocated Period complexes sequester CLOCK:BMAL1 transactivator heterodimers, hereby interrupting transcription of CCG. Proteasomal degradation fine tunes clearance of repressors from the nucleus. Reinforcing loops include the interplay between REV-ERB and ROR proteins at ROR elements (blue rectangles) in the promoters of many genes, including that of Bmal1. Additionally, certain transcription factors are clock controlled, as exemplified by the PAR-bZip family including the activators DBP, TEF, and HLF and the repressor NFIL3. Through binding to D-boxes in the genome (red rectangles), these can impose rhythmicity to specific genetic programs, such as demonstrated for components of the cytochrome P450 system in the mouse liver [106]. b Distinct epigenetic regulatory layers coordinate circadian transcriptional output. Tissue-specific transcription factors, nuclear receptors, or master regulators of intracellular signaling can determine a portion of the circadian transcriptome in response to environmental cues. Additionally, epigenetic modifications including DNA methylation or histone marks are highly dynamic and shape circadian transcription. Indeed, the global nuclear architecture has been demonstrated to coordinate transitions between transcriptionally active and repressive states during the circadian cycle 
transcription [19] (Fig. 1a). Additional motifs involved in rhythmic gene expression are D-box elements, which are recognized by the PAR-bZip (proline and acidic amino acid-rich basic leucine zipper) activating transcription factors DBP (D-box binding protein), TEF (thyrotroph embryonic factor) and HLF (hepatic leukemia factor), and the repressor NFIL3 (nuclear factor, interleukin-3 regulated; also known as E4BP4). Remarkably, expression of PAR-bZip activators is driven by the core clock TTFL through binding to E-boxes in their promoters, while that of the repressor NFIL3 is preferably controlled by ROREs (Fig. 1a). This allows for the temporally segregated expression of activators and repressors, which in turn impose rhythmicity to subsidiary genes.

In this scenario, tissue-specific oscillations for distinct transcripts represent a challenge for fully understanding circadian transcription. Recent advances point towards the combinatory action of transcription factors, which could account for acrophase or amplitude changes in oscillatory transcripts in a tissue-specific manner. For example, the hepatocyte nuclear factor 4A (HNF4A) interacts with the core clock complex at shared chromatin sites in the mouse liver, suggesting a regulatory mechanism in which HNF4A opposes CLOCK:BMAL1 transactivation at specific metabolic genes [20] (Fig. 1b). This molecular mechanism is also involved in circadian reprogramming in pathological states, as described for the TF NF- $\kappa \mathrm{B}$, which relocates CLOCK:BMAL1 heterodimers to new genomic sites in response to inflammatory signals in the mouse liver [21]. Also, PPAR $\alpha$ (peroxisome proliferator-activated receptor alpha) and SREBP (sterol regulatory element-binding protein 1) mediate a major rewiring of the hepatic circadian transcription of lipid-related genes in a mouse model of diet-induced obesity [22].

\section{Epigenetic control of circadian transcription}

Transcriptional cycles governed by the molecular clock occur in the chromatin fiber. It is conceptually apparent that the circadian machinery needs assistance from many chromatin factors to regulate circadian oscillations. Up-and-coming research deciphers some of these interacting factors, and recent technological developments, including high-throughput sequencing and advanced microscopy, are further contributing. Therefore, epigenetic regulation is now considered fundamental for the correct timing in gene expression. Perhaps, the first evidence implicating epigenetic regulation in the control of circadian rhythmicity was the observation of light-induced phosphorylation of histone $\mathrm{H} 3$ at Serine 10 (H3S10) in the central clock [23]. Remarkably, high throughput analyses have enlightened a rhythmic epigenome in different tissues. For example, neuronal network properties in the SCN display high plasticity in response to light/dark cycle length. Interestingly, SCN adaptation to distinct light periods relies on DNA methylation patterns at specific genes related to neurotransmitter receptors and ion channels, including several potassium, calcium, and GABA channels [24, 25]. Notably, cytosine methylation oscillates also in peripheral tissues, such as the lung and liver, and epigenetic variation due to methyl-cytosine oscillation is evident during aging [26]. Besides DNA methylation, histone posttranslational modifications (PTMs) have been implicated in cyclic transcription, including histone acetylation or distinct histone methylation patterns, all of which have been shown to oscillate at multiple genomic regions (Fig. 1b). For example, circadian rhythms in histone acetylation were first described in the promoter regions of Per1, Per2, and Cry1 genes, and a rhythmic interaction of the histone acetyltransferase (HAT) p300 with CLOCK appeared to be responsible for it [27]. Indeed, the evidence of HAT activity within the CLOCK protein reinforces the notion of an epigenetic component in the circadian clock [28]. So far, circadian rhythms in histone PTMs have been widely described in mouse liver [8, 29-31]. For example, oscillations in transcriptionally activating marks H3K4me3 and H3K9ac are apparent in the promoters of many rhythmic genes. Concomitantly, H3K9me3 repressive mark also displays circadian rhythmicity. ChIP experiments using a combination of antibodies recognizing active and inactive RNAPII, and the elongation marks H3K79me2 and H3K36me3 reveal circadian control exerted on RNAPII recruitment, activation, and elongation steps $[8,29]$. Nonetheless, rhythmic loading of RNAPII to promoters rather than its activation from a poised state is mostly responsible for cyclic gene expression in the mouse liver [32].

It is considered that the molecular clock coordinates with specific epigenetic remodelers to sustain the circadian dynamics of the epigenome [33-39]. For example, the histone methyltransferase mixed lineage leukemia 1 (MLL1) interacts with CLOCK:BMAL1 and imposes oscillatory pattern to the H3K4me3 activating epigenetic mark at the promoters of Dbp and Per1 [38]. Interestingly, MLL1 circadian enzymatic activity appears to be directed by posttranslational modifications consisting of rhythmic acetylation at K1130 and K1133 [39]. MLL1 acetylation potentiates its catalytic activity, while deacetylation mediated by the deacetylase sirtuin1 (SIRT1) is inhibitory; thereby, cyclic MLL1 acetylation can be detected in mouse embryonic fibroblasts and mouse liver [39]. Similarly, oscillatory histone acetylation is assisted through partnering with the HATs p300 and CBP, which appear rhythmically recruited to specific genomic loci $[8,27,40,41]$. Additional chromatin remodelers involved in circadian control include the NuRD 
(nucleosome remodeling deacetylase) transcriptional corepressor complex, which contains the ATP-dependent nucleosome remolding CHD4 (chromodomain-helicase-DNA-binding protein 4) [42]. Hence, NuRD corepressor interacts and assists PER complexes to silence transcription [42]. A rhythmic epigenome is central to determine the cell-type-specific circadian transcriptional output, ultimately imposing oscillations on biological pathways that temporally segregate metabolism around the day. For example, the histone deacetylase HDAC3 synchronizes circadian lipid and glucose metabolism in mouse liver and muscle and is rhythmically recruited to chromatin within a repressor complex directed by the circadian protein REV-ERB $\alpha$ [43-45]. Rhythmic HDAC3 recruitment directs oscillations in $\mathrm{H} 3 \mathrm{~K} 9$ acetylation and chromatin compaction at lipid biosynthetic genes, a molecular mechanism underlying the diurnal rhythm observed in hepatic lipogenesis [45].

Environmental cues altering circadian rhythms prompt a major reprogramming of the circadian transcriptome where epigenetic mechanisms become essential [46]. It is conceptually evident that the clock machinery senses metabolic states to adapt its function accordingly, and several epigenetic mechanisms have been described linking metabolic cues with the molecular clock [6]. For example, SIRT1 deacetylase activity is coupled to the hydrolysis of the metabolite $\mathrm{NAD}^{+}$(nicotinamide adenine dinucleotide, oxidized) in a way that endogenous fluctuations of $\mathrm{NAD}^{+}$levels determine SIRT1 function [47]. Because SIRT1 also regulates clock function, it is considered a nutrient sensor that connects intracellular energy state to the clock [46]. Interestingly, JmJC domain-containing histone demethylases such as KDM5A (lysine-specific demethylase 5A) relate oxygen sensing to chromatin in a way that, in hypoxic conditions, H3K4me3 and H3K36me3 activating histone modifications are increased $[48,49]$. Indeed, KDM5A participates in circadian oscillator function and influences histone acetylation levels at the Per2 promoter [50]. It is tempting to speculate that KDM5A functions as an oxygen sensor connecting epigenetic responses to the circadian clock in normoxic and hypoxic conditions [51,52].

Intriguingly, latest discoveries pinpoint an unexpected epigenetic regulatory layer of circadian transcription, being higher order genome topology and nuclear architecture (Fig. 1b). Not only do epigenetic mechanisms regulate cyclic transcription, but they also establish chromatin loops or long-range interactions and determine the spatial distribution of circadian genes in the nuclear space. To introduce the current understanding on nuclear architecture, we have discussed it in the next section. Thereafter, we have dissected the regulatory role of chromatin topology in circadian control of gene expression.

\section{Spatial organization of the genome}

How the genome organizes inside of the nucleus has been a permanent question for the chromatin biology field. The nucleosome is considered as the basic unit of the chromatin and is composed by a histone octamer wrapped by 145 to 147 base pairs of DNA [53]. However, a human diploid cell nucleus contains roughly 30 million nucleosomes, which must be somehow organized to provide the framework for the genome functions. Basically, the combination of two technical approaches has provided the knowledge on these major questions; these are microscopy approaches and chromosome conformation capture (3C)-based techniques. Remarkably, outstanding and recent advances in photonics, biophysics, next-generation sequencing, single cell analyses, and computational approaches have set the basis for our current and profound understanding of genome folding within the nuclear space [54]. Still, many questions remain to be addressed, amongst these are the precise impact of nuclear architecture on genome functions such as transcription or DNA repair, or the dynamics of the $3 \mathrm{D}$ genome during processes occurring at different time scales, such as cell cycle, cellular differentiation, environmental adaptation, or circadian cycles.

Direct evidences of the arrangement of chromosomes in interphase were provided by the visualization of chromosome territories (CT) using fluorescence in-situ hybridization techniques (FISH) [55] (Fig. 2a). Particularly, labeling chromosomes simultaneously in single cells using a combination of fluorochromes reveals that each chromosome occupies a specific area within the nucleus [56]. Interestingly, chromosome positioning is nonrandom and displays evolutionary conserved features [57]. For example, gene-rich and small-sized chromosomes are located closer to the center of the nucleus than gene-poor or larger chromosomes, which are generally displaced towards the periphery [58-60]. The organization of chromosomes in discrete areas is further confirmed by the $3-\mathrm{C}$ derivate techniques, $4 \mathrm{C}$ and $\mathrm{Hi}-\mathrm{C}$, where contacts within chromosome are much more frequent than between different chromosomes [61-63]. Indeed, functional relevance to chromosome positioning might be related to transcriptional rates, as actively transcribed genes are preferentially in a more internal position [64].

Principles of genome folding have been uncovered using $\mathrm{Hi}-\mathrm{C}$ techniques, and the organization into two main structural and functional compartments, termed A and $\mathrm{B}$, is apparent. Technically, $\mathrm{A} / \mathrm{B}$ compartments are determined by a principal component analysis of normalized Hi-C data contact matrices [63, 65] (Fig. 2b). Structurally, each compartment behaves as a unit containing either open, transcriptionally active chromatin (A compartment) or silent, heterochromatic regions 


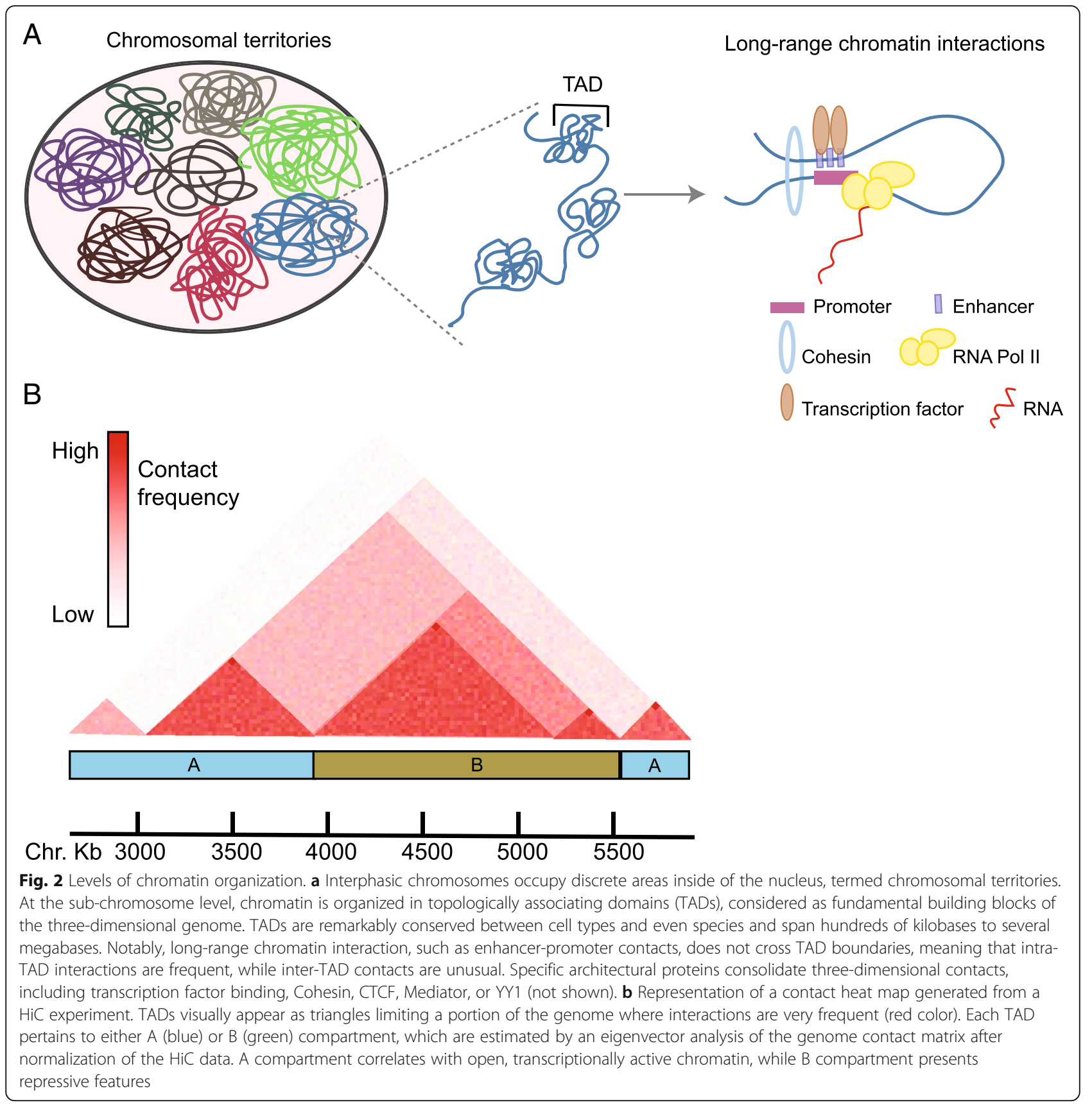

(B compartment). Moreover, chromatin within A compartment is gene dense and enriched in activating epigenetic marks, while compartments of type B segregate regions much more resistant to DNAse digestion and marked with heterochromatic histone modifications, such as H3K9me3. Functionally, A and B compartments correlate with early and late replications times respectively and segregate chromatin regions with distinct transcriptional states [66]. At the megabase and sub-megabase scales, the genome appears organized in segments with very high interaction frequencies within, separated from each other by boundaries which sharply limit the interactions between them. These structural units are termed topologically associating domains (TADs), which spatially divide the linear genome into three-dimensional units (Fig. 2). Inside each TAD, numerous chromatin loops arrange the specific enhancerpromoter interactions, positioning of insulator elements, functionality of locus control regions, etc. Interestingly, the boundaries limiting TADs in mammals are largely constant across different cell types [67-69]. These boundaries provide isolation to regulatory elements such as enhancers, in a way that they influence expression of specific genes within the same TAD, but are excluded 
from contacting and regulating genes pertaining to any other TAD [70-72]. The architectural proteins CTCF (CCCTC-binding factor) and cohesin play major roles in maintaining genome topology, but other factors such as the Mediator complex, YY1 (Ying Yang 1), and even non-coding RNAs also intervene, while a constant source of ATP is necessary for adequate establishment of loop domains [73-76] (Fig. 2).

Recent research point towards a crucial role for transcription factors (TFs) in shaping genome topology during cell reprogramming and differentiation. For example, cell-type-specific contacts between loci bound by distinct transcription factors are apparent during neural differentiation [77]. Some of these TFs include the neural master regulator Pax6 (Paired box 6) or the neuronal TFs NeuroD2 and TBR1 (T-box, brain, 1) [77]. Moreover, the TF Pax5 (Paired box 5) drives lineage-specific genome architecture during $\mathrm{B}$ cell differentiation [78]. Remarkably, the Yamanaka factors OCT4 (octamer-binding transcription factor 4), NANOG (Nanog homeobox), and SOX2 (sex determining region Y-box 2) dictate gene regulation during B cell reprogramming by inducing sequential changes in genome topology and chromatin states [79]. Indeed, chromatin accessibility measured by ATAC-seq and H3K4me2 dynamics is initially lost at lineage-specific gene-regulatory elements, and subsequently an open chromatin state is established at pluripotency genes [79]. This reprogramming trajectory is accompanied by variations in genome compartmentalization which are coherent with the observed transcriptional rewiring [79]. Collectively, these evidences implicate TFs as drivers of topological fluctuations in the genome, and genome topology as a framework for delineating cell fate in mammals. However, how transcriptional reprogramming relates to nuclear architecture during cellular processes requiring shorter time scales remains highly elusive. In this line, the circadian program of gene expression provides the ideal scenario to uncover these questions.

\section{Beyond circadian transcription: genome topology assists rhythmicity}

It is being increasingly recognized that the spatial organization of the genome in the interphase nucleus constitutes a regulatory layer coordinating chromatin functions, and the circadian program of gene expression is not an exception. Increasing evidence demonstrates that spatial organization of circadian genes in the nucleus assists rhythmic expression [6].

Perhaps the first evidence suggesting circadian rhythms in DNA topology comes from studies in the green alga Chlamydomonas reinhardtii [80], where the DNA supercoiling in the chloroplast was found to oscillate with a diurnal rhythm. Moreover, this endogenous fluctuation tightly correlates with circadian gene expression in the chloroplast, suggesting a direct link between DNA topology and rhythmic transcription [80]. A similar scenario has been described in the unicellular cyanobacterium Synechococcus elongatus, where the circadian clock controls transcription of virtually the entire genome [81]. In general, the bacterial chromosome is compacted into a highly organized structure termed "nucleoid," based on condensation and coiling of DNA [82]. Interestingly, $S$. elongatus shows circadian rhythms in chromosome compaction which can drive oscillations in gene expression and determine the circadian transcriptional output [83-85]. These topological rhythms in the nucleoid are directed by the endogenous clock $[84,85]$.

In Arabidopsis thaliana, the master zeitgeber, light, can trigger rapid spatial repositioning of a group of circadian genes including $C A B$ (chlorophyll a/b-binding protein), $R B C S$ (ribulose-1,5-bisphosphate carboxylase/ oxygenase small subunit), and $P C$ (phytochelatin synthase), relocating them from the nuclear interior to the periphery, thus leading to transcription [86]. Along the same line, exposure to light during germination triggers massive changes in nuclear architecture and RNA PolII relocation, a process involving the circadian cryptochrome photoreceptors $[87,88]$. These evidences indicate that the spatial organization of the genome inside of the nucleus is influenced by the circadian clock. Interestingly, the spatial positioning of the core clock gene Bmal1 in mammals might be important for circadian control, as the promoter of this gene is bound by the nuclear membrane protein MAN1 (MAN antigen 1), thereby activating its transcription [89]. Additionally, genetic disruption of certain components of the nuclear envelope such as LMN1B (lamin 1-B) or LBR (lamin B receptor) impact circadian amplitude and period length [89], strengthening a role for nuclear architecture in assisting the circadian oscillator. Indeed, in human HCT116 cells, the cyclic gene PARD3 (partitioning defective 3 homolog) is rhythmically recruited to the nuclear periphery through a molecular interplay driven by CTCF and PARP1 (poly [ADP-ribose] polymerase 1) [90].

Using chromosome conformation capture on ChIP (4C) technology, it was demonstrated that circadian genes in mouse embryonic fibroblasts (MEFs) are organized in functional territories inside of the nucleus (Fig. 3) [61]. Interestingly, the circadian clock has a role in fine tuning certain temporal changes in genome organization. Using the circadian gene $D b p$ as a bait for $4 \mathrm{C}$ analyses, it was shown that cyclic chromosomal arrangements accompany circadian transcription, hence delineating a circadian interactome [61]. These genomic interactions are much less dynamic in MEFs (mouse embryonic fibroblasts) lacking the core clock gene Bmal1, indicating a prevalent role for the circadian 


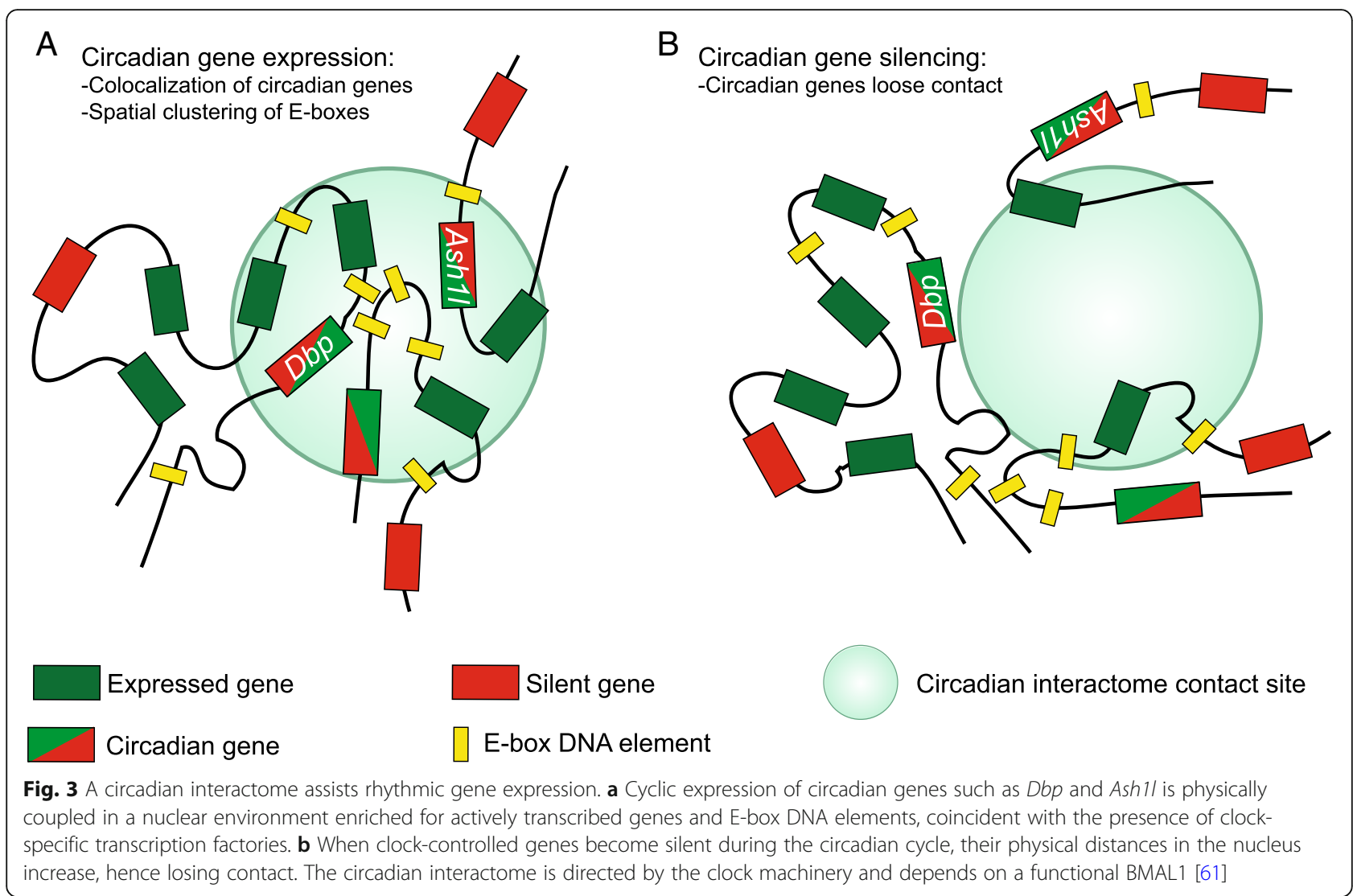

machinery in supporting fluctuations in the nuclear landscape. Some of the genes located at the $D b p$ circadian interactome are rhythmically transcribed, and their phase closely follows that one from $D b p$. These evidences suggest that CLOCK:BMAL1-directed transcription occurs in dedicated transcription factories. Supporting this idea, a significant spatial congregation of circadian E-box elements is observed around $D b p$ gene [61]. Hence, as previously reported for different transcriptional networks, the circadian program of gene expression in MEFs happens in pre-established nuclear domains (Fig. 3) [6, 91]. Additional transcription factor binding sites are highly represented in the $D b p$ circadian interactome, indicating that combinatorial associations with multiple DNA elements provides a spatial framework for circadian transcription. Intriguingly, the genes in physical proximity from $D b p$ pertain to biological pathways known to be circadian, such as chromatin regulation or xenobiotic detoxification, suggesting the presence of specialized transcription factories regulating circadian gene networks.

These evidences have been reinforced using a whole genome approach termed $\mathrm{HiC}$ in human fibroblasts, where temporal dynamics in nuclear architecture is also apparent $[92,93]$. Indeed, relative physical distances between the core clock genes PER2 and CLOCK during the circadian cycle serve as a predictor of their transcriptional activity [92]. Moreover, several circadian interactomes with co-regulated circadian genes also appear in human fibroblasts, suggesting that specialized and dynamic nuclear hubs participate in the regulation of circadian transcription [92]. Intriguingly, in both human and mouse-derived fibroblasts, the H3K36 methyltransferase coding gene ASH1L (Ash1l; absent, small, or homeotic-like) is dynamically coupled inside a circadian interactome with additional rhythmically expressed and cell-type-specific genes (Fig. 2), strongly suggesting a role for ASH1L in chromatin remodeling associated to circadian nuclear topology [61, 92].

\section{Mammalian circadian genome topology: lessons from mouse liver}

Recent studies in mouse liver demonstrate that dynamic genome topology shapes circadian gene transcription. Indeed, $\mathrm{HiC}$ and $4 \mathrm{C}$ techniques reveal that circadian chromatin loops happen in cis to coordinate liver-specific enhancer-promoter interactions, driving transcription $[9,94,95]$. This has been demonstrated for the clock gene Cry1, which depicts a dynamic loop between the TSS and an enhancer located within the first Cry1 intron $[94,95]$. This contact appears at night (ZT20-22; ZT stands for zeitgeber time), preceding the peak of 
expression of Cry1. Indeed, genetic ablation of the intronic region involved in this dynamic contact in mice impacts circadian behavior by shortening period length, because of constitutive Cry1 gene silencing [94] (Fig. 4a). Remarkably, this circadian interaction is driven by the clock molecular machinery, and particularly, by rhythmic REV-ERB $\alpha$ binding during the daytime, which in turn impedes loop formation. Interestingly, REV-ERB $\alpha$ functionally opposes enhancer-promoter loop formation at a number of rhythmic genes in the liver by obstructing recruitment of the general looping factor mediator (MED1) and the reader of H3K27ac BRD4 (Bromodomain-containing protein 4) (Fig. 4a) [95]. Importantly, most of BMAL1-target genes transcriptional oscillations in the mouse liver rely on functional interactions between regulatory elements, which appear increased during the phase of BMAL1 recruitment to chromatin, around ZT6 [96]. Together, these evidences highlight the fundamental role of chromatin looping in regulating circadian transcription and identify new molecular actors which are critical to maintain dynamic chromosomal interactions.

A large amount of genomic and epigenomic data in the circadian field has been generated from mouse liver, while information from other tissues is mostly lacking. However, the circadian transcriptome has been explored
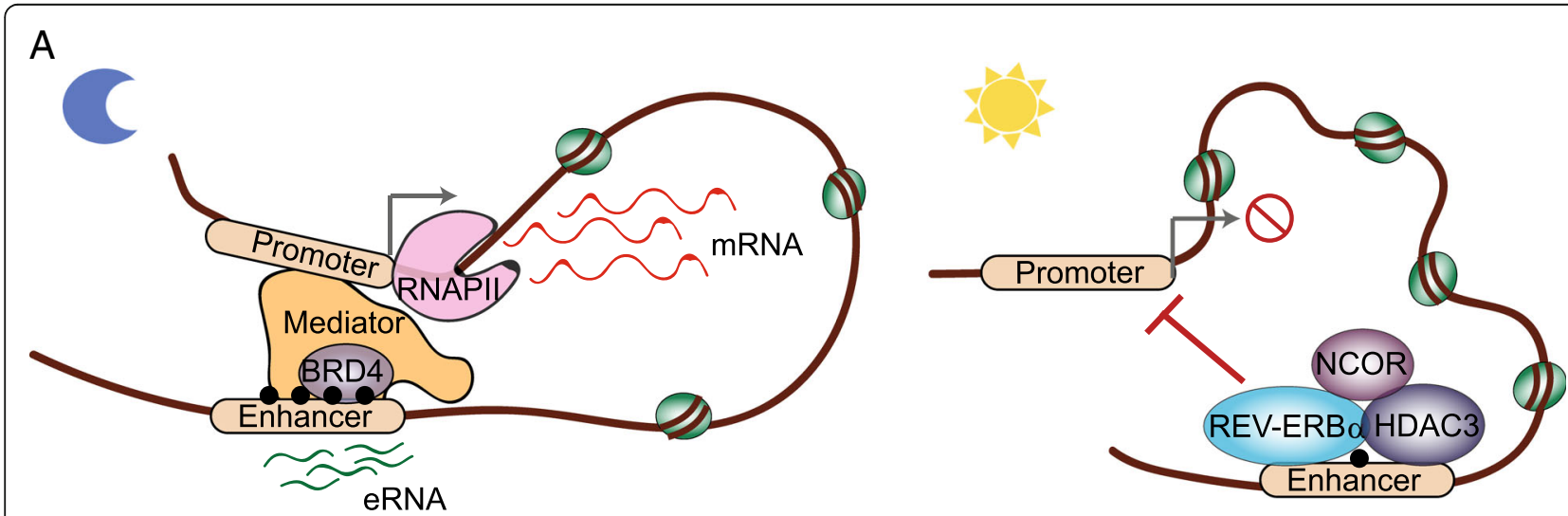

B
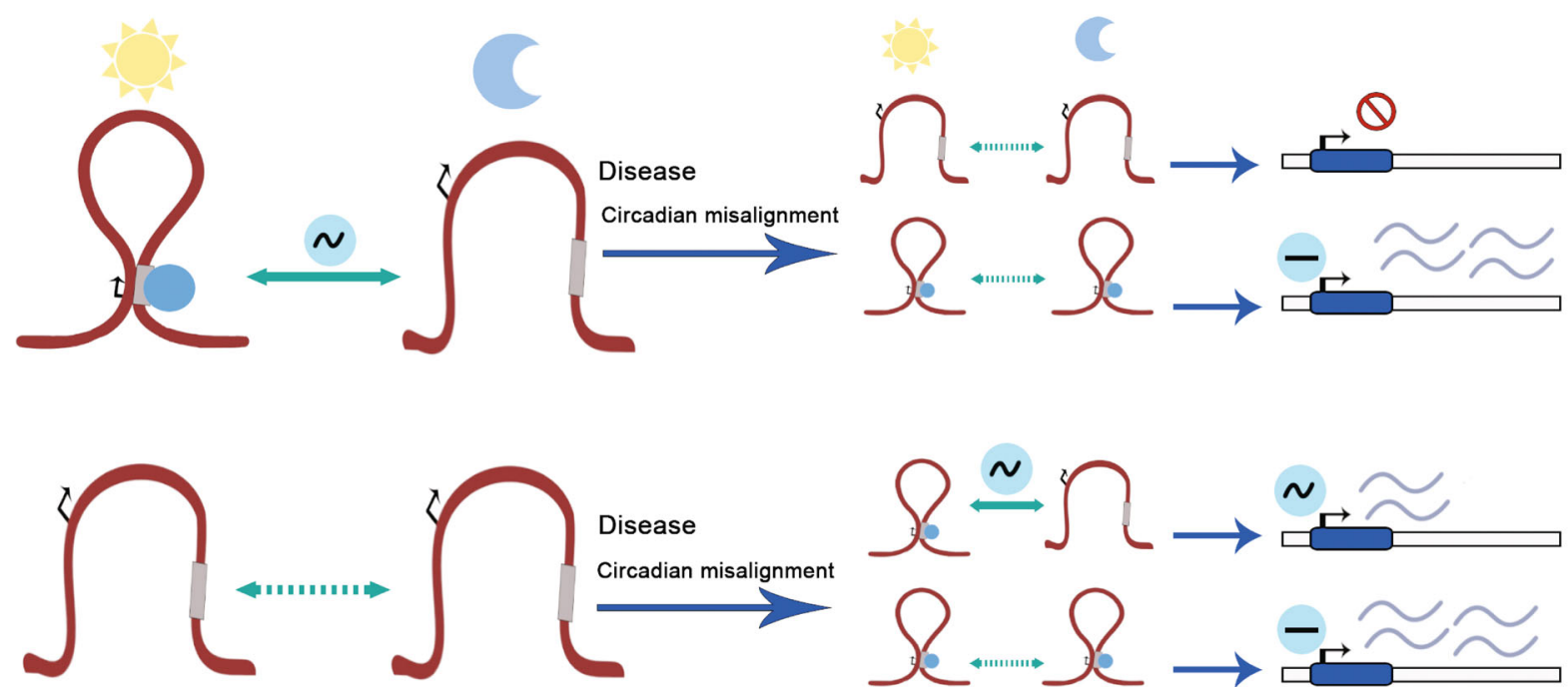

Fig. 4 Circadian chromatin interactions in health and disease. a Many circadian long-range interactions direct enhancer-promoter contacts at a specific time of day and in a tissue-specific manner. For example, in the mouse liver, Cry 1 promoter contacts an enhancer element located within an intron, specifically at ZT22 (night time). This interaction is characterized by H3K27ac mark at the enhancer (back dots), which is recognized by BRD4 and recruits the Mediator complex. eRNAs also appear at ZT22, and Cryl gene is therefore transcribed. During the opposite phase, at ZT10 (day time), the clock protein REVERBa displaces Mediator and BRD4 from the enhancer region and recruits a repressor complex containing NCOR and the deacetylase HDAC3. The active enhancer marks H3K27ac and eRNA decrease and Cry1 transcription ceases [95]. b During the day, some chromatin interactions oscillate while others remain constant. Misalignment of circadian rhythms or certain pathological states could trigger different scenarios: circadian contacts could be disrupted leading, for example, to a permanent interaction of the absence of it (upper panel). Additionally, some new interactions may appear, either oscillatory or not (lower panel). These alterations may cause distinct patterns of gene expression as observed in certain pathological conditions, including cancer and cognitive or metabolic diseases 
across many tissues. A comparative analysis that integrates TF binding site predictions with rhythmic mRNA accumulation suggests that the clock TFs can colocalize with tissue-specific TFs, such as FOXA2 (forkhead box protein A2) and HNF6 (hepatocyte nuclear factor 6) in the liver, which in turn can mediate tissue-specific looping, thereby shaping a particular circadian transcriptome for each tissue or cell type $[9,96]$. This notion is further reinforced by the identification of circadian activity of enhancer regions based on enhancer RNA (eRNA) transcription [97, 98]. It is generally accepted that these non-coding RNAs are implicated in long-range looping interactions and constitute a molecular signature of active enhancers [98]. Indeed, eRNAs expressed between ZT6-ZT9 are enriched in E-boxes, while those accumulated around ZT18-ZT24 contain RevDR2 and RORE motifs. Interestingly, circadian eRNAs in the mouse liver are constitutively enriched for the Forkhead box (FOX) and HNF4 motifs [97]. Since eRNAs are most probably located at looping sites, it is tempting to speculate that FOXO1 (forkhead box protein O1) and HNF4 TFs could also mediate liver-specific chromatin interactions.

An important question remains whether enhancer-promoter interactions could be the trigger of distinct genetic programs of gene expression in response to environmental challenges [46]. Recent research points into this direction. For example, in the mouse liver, feeding-mediated gene repression is accompanied by decreased H3K27ac mark at sites enriched for motifs known to interact with the glucocorticoid receptor (GR), cAMP responsive element binding protein (CREB), and FOX TFs [99], suggesting that these could mediate transcriptional reprogramming in response to feeding through dynamic chromatin looping. Moreover, circadian eRNAs are reprogrammed upon high-fat diet feeding, and some new eRNAs become oscillatory, while others display phase shifts. Interestingly, SREBP1 and PPAR $\alpha$ TFs are required for cyclic expression of newly oscillating eRNAs in high-fat diet fed mice near some de novo lipogenesis and fatty acid oxidation genes, such as Fasn (fatty acid synthase), Acaca (acetyl-CoA carboxylase 1), Acox1 (acyl-CoA oxidase 1), or Aldh3a2 (aldehyde dehydrogenase 3 family member A2) [22]. In this scenario, it is tempting to speculate that alterations in genome topology or the arrangement of certain contact patterns between critical regulatory elements may establish a specific chromatin conformation leading to the circadian transcriptional reorganization observed under many pathological conditions, including metabolic diseases, cognitive disorders, or even cancer (Fig. 4b) [100-102].

\section{Conclusion}

The dynamic interplay between spatial organization of the genome and the circadian gene expression program is emerging. Up-and-coming research highlights a remarkable plasticity on chromatin states and genome dynamics during the circadian cycle, and epigenetic transitions appear to be at the core of transcriptional reprogramming triggered by environmental cues. Components of the molecular clock, including BMAL1 and REVERB $\alpha$, emerge as important regulators of dynamic interactions in the three-dimensional genome during the circadian cycle. However, the role of the circadian machinery in defining functional regulatory elements in response to environmental challenges remains to be understood. Growing our understanding on these mechanisms will remarkably benefit from recent technological advances on molecular imaging of live cells [103]. For example, imagining endogenous loci using fluorescently labeled CRISPR/dCas system in live cells could provide means to reveal the significance of spatiotemporal organization and dynamics of chromatin during the circadian cycle. Moreover, intracellular distribution of metabolites serving as coenzymes for epigenetic regulators, such as $\mathrm{NAD}^{+}$, is generally diminished [104]. Hence, it will be of interest to determine if local concentrations of specific metabolites in nuclear microenvironments control the activity of epigenetic remodelers in a highly dynamic and locally restricted regulatory level.

All these findings provide an exciting scenario to investigate circadian regulation of pathological states and constitute starting points to uncover precise molecular links that couple the circadian clock with metabolic control, epigenetic regulation, and environmentally triggered phenotypes (Fig. 4b). For example, further research is necessary to reveal functional relationships between the molecular clock and the epigenetic reprogramming associated to distinct feeding patterns, which could pave the way to highly effective chronotherapeutic approaches for the treatment of metabolic pathologies. Finally, advancing our knowledge along these lines could provide means to further understand the implications of genetic variation within non-coding regulatory elements for human disease [105].

\footnotetext{
Abbreviations

3C: Chromosome conformation capture; Acaca: Acetyl-CoA carboxylase 1; Acox1: Acyl-CoA oxidase 1; Aldh3a2: Aldehyde dehydrogenase 3 family member A2; ASH1L: (Absent, small, or homeotic)-like; ATAC-seq: Assay for transposase-accessible chromatin sequencing; ATP: Adenosine triphosphate; BMAL1: Brain and muscle ARNT-like protein-1; BRD4: Romodomaincontaining protein 4; CAB: Chlorophyll a/b-binding protein;

CHD4: Chromodomain-helicase-DNA-binding protein 4; ChIP: Chromatin immunoprecipitation; CLOCK: Circadian Locomotor Output Cycles Kaput; CREB: CAMP responsive element binding protein; CRY: Cryptochrome; $C T$ : Chromosome territories; CTCF: CCCTC-binding factor; DBP: Albumin-Dsite-binding protein; DNA: Deoxyribonucleic acid; eRNA: Enhancer RNA; Fasn: Fatty acid synthase; FISH: Fluorescence in-situ hybridization; FOX: Forkhead box; FOXA2: Forkhead box protein A2; FOXO1: Forkhead box protein O1; GR: Glucocorticoid receptor; H3: Histone 3; HAT: Histone acetyltransferase; HDAC3: Histone deacetylase 3; HLF: Hepatic leukemia factor; HNF4A: Hepatocyte nuclear factor 4A; HNF6: Hepatocyte nuclear
} 
factor 6; KDM5A: Lysine-specific demethylase 5A; LBR: Lamin B receptor; LMN1B: Lamin 1-B; MAN1: MAN antigen 1; MEF: Mouse embryonic fibroblasts; MLL1: Mixed lineage leukemia 1; NAD ${ }^{+}$: Nicotinamide adenine dinucleotide, oxidized; NANOG: Nanog homeobox; NFIL3: Nuclear factor, interleukin-3 regulated; NF-kB: Nuclear factor kappa-light-chain-enhancer of activated B cells; NR: Nuclear receptor; NuRD: Nucleosome remodeling deacetylase; OCT4: Octamer-binding transcription factor 4; PAR-bZip: Proline and acidic amino acid-rich basic leucine zipper; PARD3: Partitioning defective 3 homolog; PARP1: Poly [ADP-ribose] polymerase 1; Pax5: Paired box 5; Pax6: Paired box 6; PC: Phytochelatin synthase; PER: Period; PPARa: Peroxisome proliferator-activated receptor alpha; PTM: Posttranslational modifications; RBCS: Ribulose-1,5-bisphosphate carboxylase/oxygenase small subunit; REV-ERB: Reverse erythroblastosis virus; RNA: Ribonucleic acid; RNAPII: RNA polymerase II; ROR: Retinoic acid-related orphan receptor; RORE: Retinoic acid-related orphan receptor-binding element; SCN: Suprachiasmatic nucleus; SIRT1: Sirtuin1; SOX2: (Sex determining region Y)-box 2; SREBP1: Sterol regulatory element-binding protein 1; TAD: Topologically associating domain; TBR1: T-box, brain, 1; TEF: Thyrotroph embryonic factor; TF: Transcription factor; TSS: Transcription start site; TTFL: Transcriptional/translational feedback loops; YY1: Yin Yang 1; ZT: Zeitgeber time

\section{Acknowledgements}

We thank all the members from LA-A lab, and particularly to M.Sc. Marcia Bustamante Zepeda, for helpful discussions. This work was supported by grants PAPIIT IA201717, IN210619 from Universidad Nacional Autónoma de México, the Early Career Return Grant CRP/MEX16-05_EC from The International Center for Genomic Engineering and Biotechnology, and grant RGY0078/2017 from the Human Frontier Science Program to LA-A. IP-B and FB-P are graduated students in the Programa de Maestría Doctorado en Ciencias Bioquímicas, Universidad Nacional Autónoma de México, and received a scholarship from Consejo Nacional de Ciencia y Tecnología, Mexico. We apologize to the authors whose studies we could not discuss or cite due to space limitations.

\section{Funding}

This work was supported by grants PAPIIT IA201717 from Universidad Nacional Autónoma de México, the Early Career Return Grant CRP/MEX1605_EC from The International Center for Genomic Engineering and Biotechnology, and grant RGY0078/2017 from Human Frontier Science Program to LA-A. These grants support the research in LA-A lab. IP-B and FB$P$ are graduated students in the Programa de Maestría Doctorado en Ciencias Bioquímicas, Universidad Nacional Autónoma de México, and received a scholarship from Consejo Nacional de Ciencia y Tecnología, Mexico. These scholarships finance the student's salaries.

\section{Availability of data and materials}

Not applicable.

\section{Authors' contributions}

All authors contributed to the content. All authors read and approved the final manuscript.

\section{Ethics approval and consent to participate} Not applicable.

\section{Consent for publication}

Not applicable.

\section{Competing interests}

The authors declare that they have no competing interests.

\section{Publisher's Note}

Springer Nature remains neutral with regard to jurisdictional claims in published maps and institutional affiliations.
Received: 21 February 2019 Accepted: 29 April 2019

Published online: 15 May 2019

\section{References}

1. Reinke $H$, Asher G. Crosstalk between metabolism and circadian clocks. Nature Rev Mol Cell Biol. 2019;20(4):227-41.

2. Kyriacou CP, Hastings $\mathrm{MH}$. Circadian clocks: genes, sleep, and cognition. Trends Cogn Sci. 2010;14(6):259-67.

3. Zarrinpar A, Chaix A, Panda S. Daily eating patterns and their impact on health and disease. Trends Endocrinol Metab. 2016;27(2):69-83.

4. Kelly RM, Healy U, Sreenan S, McDermott JH, Coogan AN. Clocks in the clinic: circadian rhythms in health and disease. Postgrad Med J. 2018; 94(1117):653-8

5. Rosensweig C, Green CB. Periodicity, repression, and the molecular architecture of the mammalian circadian clock. Eur J Neurosci. 2018;00:127. https://doi.org/10.1111/ejn.14254.

6. Aguilar-Arnal L, Sassone-Corsi P. Chromatin landscape and circadian dynamics: spatial and temporal organization of clock transcription. Proc Nat Acad Sci U S A. 2015;112(22):6863-70

7. Aguilar-Arnal L, Sassone-Corsi P. The circadian epigenome: how metabolism talks to chromatin remodeling. Curr Opin Cell Biol. 2013;25(2):170-6.

8. Koike N, Yoo SH, Huang HC, Kumar V, Lee C, Kim TK, et al. Transcriptional architecture and chromatin landscape of the core circadian clock in mammals. Science. 2012;338(6105):349-54.

9. Yeung J, Mermet J, Jouffe C, Marquis J, Charpagne A, Gachon F, et al. Transcription factor activity rhythms and tissue-specific chromatin interactions explain circadian gene expression across organs. Genome Res. 2018;28(2):182-91.

10. Hastings $\mathbf{M H}$, Maywood ES, Brancaccio M. Generation of circadian rhythms in the suprachiasmatic nucleus. Nat Rev Neurosci. 2018;19(8): 453-69.

11. Weaver DR, Emery P. Chapter 39 - circadian timekeeping. In: Squire LR, Berg D, Bloom FE, du Lac S, Ghosh A, Spitzer NC, editors. Fundamental neuroscience. fourth ed. San Diego: Academic Press; 2013. p. 819-45.

12. West AC, Bechtold DA. The cost of circadian desynchrony: evidence, insights and open questions. Bioessays. 2015;37(7):777-88.

13. Menet JS, Pescatore S, Rosbash M. CLOCK:BMAL1 is a pioneer-like transcription factor. Genes Dev. 2014;28(1):8-13.

14. Trott AJ, Menet JS. Regulation of circadian clock transcriptional output by CLOCK:BMAL1. PLoS Genet. 2018;14(1):e1007156.

15. Nangle SN, Rosensweig C, Koike N, Tei H, Takahashi JS, Green CB, et al. Molecular assembly of the period-cryptochrome circadian transcriptional repressor complex. Elife. 2014;3:e03674.

16. Ode KL, Ueda HR. Design principles of phosphorylation-dependent timekeeping in eukaryotic circadian clocks. Cold Spring Harb Perspect Biol. 2018;10(8).

17. Hirano A, Fu YH, Ptacek $L J$. The intricate dance of post-translational modifications in the rhythm of life. Nat Struct Mol Biol. 2016;23(12):1053-60.

18. Zhang R, Lahens NF, Ballance HI, Hughes ME, Hogenesch JB. A circadian gene expression atlas in mammals: implications for biology and medicine. Proc Natl Acad Sci. 2014;111(45):16219-24.

19. Fang B, Lazar MA. Dissecting the Rev-erbalpha cistrome and the mechanisms controlling circadian transcription in liver. Cold Spring Harb Symp Quant Biol. 2015;80:233-8.

20. Qu M, Duffy T, Hirota T, Kay SA. Nuclear receptor HNF4A transrepresses CLOCK:BMAL1 and modulates tissue-specific circadian networks. Proc Natl Acad Sci. 2018;115(52):E12305-E12.

21. Hong HK, Maury E, Ramsey KM, Perelis M, Marcheva B, Omura C, et al. Requirement for NF-kappaB in maintenance of molecular and behavioral circadian rhythms in mice. Genes Dev. 2018;32(21-22):1367-79.

22. Guan D, Xiong Y, Borck PC, Jang C, Doulias PT, Papazyan R, et al. Dietinduced circadian enhancer remodeling synchronizes opposing hepatic lipid metabolic processes. Cell. 2018;174(4):831-42 e12.

23. Crosio C, Cermakian N, Allis CD, Sassone-Corsi P. Light induces chromatin modification in cells of the mammalian circadian clock. Nat Neurosci. 2000; 3(12):1241-7.

24. Azzi A, Dallmann R, Casserly A, Rehrauer H, Patrignani A, Maier B, et al. Circadian behavior is light-reprogrammed by plastic DNA methylation. Nat Neurosci. 2014;17(3):377-82.

25. Azzi A, Evans JA, Leise T, Myung J, Takumi T, Davidson AJ, et al. Network dynamics mediate circadian clock plasticity. Neuron. 2017;93(2):441-50. 
26. Oh G, Ebrahimi S, Carlucci M, Zhang A, Nair A, Groot DE, et al. Cytosine modifications exhibit circadian oscillations that are involved in epigenetic diversity and aging. Nat Commun. 2018;9(1):644.

27. Etchegaray J-P, Lee C, Wade PA, Reppert SM. Rhythmic histone acetylation underlies transcription in the mammalian circadian clock. Nature. 2003; 421(6919):177-82.

28. Doi M, Hirayama J, Sassone-Corsi P. Circadian regulator CLOCK is a histone acetyltransferase. Cell. 2006;125(3):497-508.

29. Le Martelot G, Canella D, Symul L, Migliavacca E, Gilardi F, Liechti R, et al. Genome-wide RNA polymerase II profiles and RNA accumulation reveal kinetics of transcription and associated epigenetic changes during diurnal cycles. PLoS Biol. 2012;10(11):e1001442.

30. Valekunja UK, Edgar RS, Oklejewicz M, van der Horst GT, O'Neill JS, Tamanini F, et al. Histone methyltransferase MLL3 contributes to genome-scale circadian transcription. Proc Natl Acad Sci U S A. 2013;110(4):1554-9.

31. Vollmers C, Schmitz Robert J, Nathanson J, Yeo G, Ecker Joseph R, Panda S Circadian oscillations of protein-coding and regulatory RNAs in a highly dynamic mammalian liver epigenome. Cell Metabolism. 2012;16(6):833-45.

32. Takahashi JS. Transcriptional architecture of the mammalian circadian clock. Nat Rev Genet. 2016;18:164.

33. Nakahata Y, Kaluzova M, Grimaldi B, Sahar S, Hirayama J, Chen D, et al. The NAD+-dependent deacetylase SIRT1 modulates CLOCK-mediated chromatin remodeling and circadian control. Cell. 2008;134(2):329-40.

34. Brown SA, Ripperger J, Kadener S, Fleury-Olela F, Vilbois F, Rosbash M, et al. PERIOD1-associated proteins modulate the negative limb of the mammalian circadian oscillator. Science. 2005;308(5722):693-6.

35. Nam Hye J, Boo K, Kim D, Han D-H, Choe Han K, Kim Chang R, et al. Phosphorylation of LSD1 by PKCa Is Crucial for Circadian Rhythmicity and Phase Resetting. Molecular Cell. 2014;53(5):791-805.

36. Duong HA, Weitz CJ. Temporal orchestration of repressive chromatin modifiers by circadian clock Period complexes. Nat Struct Mol Biol. 2014;21(2):126-32.

37. Etchegaray JP, Yang X, DeBruyne JP, Peters AH, Weaver DR, Jenuwein T, et al. The polycomb group protein EZH2 is required for mammalian circadian clock function. J Biol Chem. 2006;281(30):21209-15.

38. Katada S, Sassone-Corsi P. The histone methyltransferase MLL1 permits the oscillation of circadian gene expression. Nat Struct Mol Biol. 2010;17(12):1414-21.

39. Aguilar-Arnal L, Katada S, Orozco-Solis R, Sassone-Corsi P. NAD(+)-SIRT1 control of H3K4 trimethylation through circadian deacetylation of MLL1. Nat Struct Mol Biol. 2015;22(4):312-8.

40. Lee $Y$, Lee J, Kwon I, Nakajima Y, Ohmiya Y, Son GH, et al. Coactivation of the CLOCK-BMAL1 complex by CBP mediates resetting of the circadian clock. J Cell Sci. 2010;123(Pt 20):3547-57.

41. Xu H, Gustafson CL, Sammons PJ, Khan SK, Parsley NC, Ramanathan C, et al. Cryptochrome 1 regulates the circadian clock through dynamic interactions with the BMAL1 C terminus. Nat Struct Mol Biol. 2015;22(6):476-84.

42. Kim Jin Y, Kwak Pieter B, Weitz Charles J. Specificity in circadian clock feedback from targeted reconstitution of the NuRD corepressor. Molecular Cell. 2014;56(6):738-48.

43. Emmett MJ, Lazar MA. Integrative regulation of physiology by histone deacetylase 3. Nature Rev Mol Cell Biol. 2019;20(2):102-15.

44. Hong S, Zhou W, Fang B, Lu W, Loro E, Damle M, et al. Dissociation of muscle insulin sensitivity from exercise endurance in mice by HDAC3 depletion. Nat Med. 2017;23(2):223-34.

45. Feng D, Liu T, Sun Z, Bugge A, Mullican SE, Alenghat T, et al. A circadian rhythm orchestrated by histone deacetylase 3 controls hepatic lipid metabolism. Science. 2011;331(6022):1315-9.

46. Escalante-Covarrubias Q, Aguilar-Arnal L. Environmental regulation of metabolism through the circadian clock. Current Opinion in Toxicology. 2018:8:93-101

47. Guarente L. Chapter 1 - Sirtuins, NAD+, aging, and disease: a retrospective and prospective overview. In: Guarente L, Mostoslavsky R, Kazantsev A, editors. Introductory review on sirtuins in biology, aging, and disease. Cambridge: Academic Press; 2018. p. 1-6.

48. Batie M, Frost J, Frost M, Wilson JW, Schofield P, Rocha S. Hypoxia induces rapid changes to histone methylation and reprograms chromatin. Science. 2019;363(6432):1222-6.

49. Gallipoli P, Huntly BJP. Histone modifiers are oxygen sensors. Science. 2019; 363(6432):1148-9.

50. DiTacchio L, Le HD, Vollmers C, Hatori M, Witcher M, Secombe J, et al. Histone lysine demethylase JARID1a activates CLOCK-BMAL1 and influences the circadian clock. Science. 2011;333(6051):1881-5.
51. Adamovich Y, Ladeuix B, Golik M, Koeners MP, Asher G. Rhythmic oxygen levels reset circadian clocks through HIF1alpha. Cell Metab. 2017;25(1):93-101.

52. Wu Y, Tang D, Liu N, Xiong W, Huang H, Li Y, et al. Reciprocal regulation between the circadian clock and hypoxia signaling at the genome level in mammals. Cell Metab. 2017;25(1):73-85.

53. McGinty RK, Tan S. Nucleosome structure and function. Chemical reviews. 2015;115(6):2255-73.

54. Rowley MJ, Corces VG. Organizational principles of 3D genome architecture. Nature Reviews Genetics. 2018;19(12):789-800.

55. Cremer T, Cremer M. Chromosome territories. Cold Spring Harb Perspect Biol. 2010;2(3):a003889.

56. Cremer T, Cremer C. Chromosome territories, nuclear architecture and gene regulation in mammalian cells. Nat Rev Genet. 2001;2(4):292-301.

57. Tanabe H, Muller S, Neusser M, von Hase J, Calcagno E, Cremer M, et al. Evolutionary conservation of chromosome territory arrangements in cell nuclei from higher primates. Proc Natl Acad Sci U S A. 2002;99(7):4424-9.

58. Bolzer A, Kreth G, Solovei I, Koehler D, Saracoglu K, Fauth C, et al. Threedimensional maps of all chromosomes in human male fibroblast nuclei and prometaphase rosettes. PLoS Biol. 2005;3(5):e157.

59. Boyle S, Gilchrist S, Bridger JM, Mahy NL, Ellis JA, Bickmore WA. The spatial organization of human chromosomes within the nuclei of normal and emerin-mutant cells. Human molecular genetics. 2001;10(3):211-9.

60. Heride C, Ricoul M, Kieu K, von Hase J, Guillemot V, Cremer C, et al. Distance between homologous chromosomes results from chromosome positioning constraints. J Cell Sci. 2010;123(Pt 23):4063-75.

61. Aguilar-Arnal L, Hakim O, Patel VR, Baldi P, Hager GL, Sassone-Corsi P. Cycles in spatial and temporal chromosomal organization driven by the circadian clock Nat Struct Mol Biol. 2013:20(10):1206-13.

62. Hakim O, Resch W, Yamane A, Klein I, Kieffer-Kwon KR, Jankovic M, et al. DNA damage defines sites of recurrent chromosomal translocations in B lymphocytes. Nature. 2012;484(7392):69-74.

63. Lieberman-Aiden $\mathrm{E}$, van Berkum NL, Williams L, Imakaev M, Ragoczy $T$, Telling A, et al. Comprehensive mapping of long-range interactions reveals folding principles of the human genome. Science. 2009;326(5950):289-93.

64. Shachar S, Misteli T. Causes and consequences of nuclear gene positioning. J Cell Sci. 2017;130(9):1501-8.

65. Miura H, Poonperm R, Takahashi S, Hiratani I. Practical analysis of Hi-C data: generating A/B compartment profiles. Methods in molecular biology. 2018; 1861:221-45.

66. Pope BD, Ryba T, Dileep V, Yue F, Wu W, Denas O, et al. Topologically associating domains are stable units of replication-timing regulation. Nature. 2014;515(7527):402-5.

67. Dixon JR, Jung I, Selvaraj S, Shen Y, Antosiewicz-Bourget JE, Lee AY, et al. Chromatin architecture reorganization during stem cell differentiation. Nature. 2015;518(7539):331-6.

68. Dixon JR, Selvaraj S, Yue F, Kim A, Li Y, Shen Y, et al. Topological domains in mammalian genomes identified by analysis of chromatin interactions. Nature. 2012:485(7398):376-80.

69. Rao SS, Huntley MH, Durand NC, Stamenova EK, Bochkov ID, Robinson JT, et al. A 3D map of the human genome at kilobase resolution reveals principles of chromatin looping. Cell. 2014;159(7):1665-80.

70. Lupianez DG, Kraft K, Heinrich V, Krawitz P, Brancati F, Klopocki E, et al. Disruptions of topological chromatin domains cause pathogenic rewiring of gene-enhancer interactions. Cell. 2015;161(5):1012-25.

71. Symmons O, Pan L, Remeseiro S, Aktas T, Klein F, Huber W, et al. The Shh topological domain facilitates the action of remote enhancers by reducing the effects of genomic distances. Developmental cell. 2016;39(5):529-43.

72. Schwarzer W, Abdennur N, Goloborodko A, Pekowska A, Fudenberg G, LoeMie $Y$, et al. Two independent modes of chromatin organization revealed by cohesin removal. Nature. 2017;551:51.

73. Vian L, Pekowska A, Rao SSP, Kieffer-Kwon KR, Jung S, Baranello L, et al. The energetics and physiological impact of cohesin extrusion. Cell. 2018;173(5): $1165-78$ e20.

74. Rao SSP, Huang SC, Glenn St Hilaire B, Engreitz JM, Perez EM, Kieffer-Kwon KR, et al. Cohesin loss eliminates all loop domains. Cell. 2017;171(2):305-20 e24.

75. Weintraub AS, Li CH, Zamudio AV, Sigova AA, Hannett NM, Day DS, et al. YY1 is a structural regulator of enhancer-promoter loops. Cell. 2017;171(7): 1573-88 e28.

76. Phillips-Cremins JE, Sauria ME, Sanyal A, Gerasimova TI, Lajoie BR, Bell JS, et al. Architectural protein subclasses shape 3D organization of genomes during lineage commitment. Cell. 2013;153(6):1281-95. 
77. Bonev B, Mendelson Cohen N, Szabo Q, Fritsch L, Papadopoulos GL, Lubling $Y$, et al. Multiscale 3D genome rewiring during mouse neural development. Cell. 2017;171(3):557-72 e24.

78. Johanson TM, Lun ATL, Coughlan HD, Tan T, Smyth GK, Nutt SL, et al. Transcription-factor-mediated supervision of global genome architecture maintains B cell identity. Nature Immunology. 2018;19(11):1257-64.

79. Stadhouders R, Vidal E, Serra F, Di Stefano B, Le Dily F, Quilez J, et al. Transcription factors orchestrate dynamic interplay between genome topology and gene regulation during cell reprogramming. Nat Genet. 2018; 50(2):238-49.

80. Salvador ML, Klein U, Bogorad L. Endogenous fluctuations of DNA topology in the chloroplast of Chlamydomonas reinhardtii. Mol Cell Biol. 1998;18(12): 7235-42.

81. Mori T, Johnson $\mathrm{CH}$. Circadian programming in cyanobacteria. Semin Cell Dev Biol. 2001:12(4):271-8.

82. Pruss GJ, Drlica K. DNA supercoiling and prokaryotic transcription. Cell. 1989; 56(4):521-3.

83. Smith RM, Williams SB. Circadian rhythms in gene transcription imparted by chromosome compaction in the cyanobacterium Synechococcus elongatus. Proc Natl Acad Sci U S A. 2006;103(22):8564-9.

84. Vijayan V, Zuzow R, O'Shea EK. Oscillations in supercoiling drive circadian gene expression in cyanobacteria. Proc Natl Acad Sci U S A. 2009;106(52): 22564-8.

85. Woelfle MA, Xu Y, Qin X, Johnson CH. Circadian rhythms of superhelical status of DNA in cyanobacteria. Proc Natl Acad Sci U S A. 2007;104(47): 18819-24.

86. Feng C-M, Qiu Y, Van Buskirk EK, Yang EJ, Chen M. Light-regulated gene repositioning in Arabidopsis. Nature Communications. 2014;5:3027.

87. Bourbousse C, Mestiri I, Zabulon G, Bourge M, Formiggini F, Koini MA, et al. Light signaling controls nuclear architecture reorganization during seedling establishment. Proc Natl Acad Sci U S A. 2015;112(21):E2836-44.

88. Somers DE, Devlin PF, Kay SA. Phytochromes and cryptochromes in the entrainment of the Arabidopsis circadian clock. Science. 1998;282(5393): 1488-90.

89. Lin S-T, Zhang L, Lin X, Zhang LC, Garcia VE, Tsai C-W, et al. Nuclear envelope protein MAN1 regulates clock through BMAL1. Elife. 2014;3: e02981.

90. Zhao H, Sifakis EG, Sumida N, Millan-Arino L, Scholz BA, Svensson JP, et al. PARP1- and CTCF-mediated interactions between active and repressed chromatin at the lamina promote oscillating transcription. Mol Cell. 2015; 59(6):984-97.

91. Jin F, Li Y, Dixon JR, Selvaraj S, Ye Z, Lee AY, et al. A high-resolution map of the three-dimensional chromatin interactome in human cells. Nature. 2013; 503(7475):290-4

92. Chen $\mathrm{H}$, Chen J, Muir LA, Ronquist S, Meixner W, Ljungman M, et al. Functional organization of the human 4D Nucleome. Proc Natl Acad Sci U S A. 2015:112(26):8002-7.

93. van Berkum NL, Lieberman-Aiden E, Williams L, Imakaev M, Gnirke A, Mirny $L A$, et al. Hi-C: a method to study the three-dimensional architecture of genomes. JoVE. 2010(39):e1869.

94. Mermet J, Yeung J, Hurni C, Mauvoisin D, Gustafson K, Jouffe C, et al. Clockdependent chromatin topology modulates circadian transcription and behavior. Genes Dev. 2018;32(5-6):347-58.

95. Kim YH, Marhon SA, Zhang Y, Steger DJ, Won KJ, Lazar MA. Rev-erbalpha dynamically modulates chromatin looping to control circadian gene transcription. Science. 2018;359(6381):1274-7.

96. Beytebiere JR, Trott AJ, Greenwell BJ, Osborne CA, Vitet H, Spence J, et al. Tissue-specific BMAL1 cistromes reveal that rhythmic transcription is associated with rhythmic enhancer-enhancer interactions. Genes Dev. 2019; 33(5-6):294-309.

97. Fang B, Everett LJ, Jager J, Briggs E, Armour SM, Feng D, et al. Circadian enhancers coordinate multiple phases of rhythmic gene transcription in vivo. Cell. 2014;159(5):1140-52.

98. Kim T-K, Hemberg M, Gray JM, Costa AM, Bear DM, Wu J, et al. Widespread transcription at neuronal activity-regulated enhancers. Nature. 2010;465:182.

99. Kalvisa A, Siersbaek MS, Praestholm SM, Christensen LJL, Nielsen R, Stohr O, et al. Insulin signaling and reduced glucocorticoid receptor activity attenuate postprandial gene expression in liver. PLoS Biol. 2018;16(12): e2006249.

100. Schmitt K, Grimm A, Eckert A. Amyloid-beta-induced changes in molecular clock properties and cellular bioenergetics. Front Neurosci. 2017;11:124.
101. Padmanabhan K, Billaud M. Desynchronization of circadian clocks in cancer: a metabolic and epigenetic connection. Front Endocrinol. 2017;8:136.

102. Dyar KA, Lutter D, Artati A, Ceglia NJ, Liu Y, Armenta D, et al. Atlas of circadian metabolism reveals system-wide coordination and communication between clocks. Cell. 2018;174(6):1571-85 e11.

103. Knight SC, Tjian R, Doudna JA. Genomes in focus: development and applications of CRISPR-Cas9 imaging technologies. Angewandte Chemie International Edition. 2018;57(16):4329-37.

104. Aguilar-Arnal L, Ranjit S, Stringari C, Orozco-Solis R, Gratton E, Sassone-Corsi P. Spatial dynamics of SIRT1 and the subnuclear distribution of NADH species. Proc Natl Acad Sci. 2016;113(45):12715-20.

105. Claussnitzer M, Dankel SN, Kim KH, Quon G, Meuleman W, Haugen C, et al. FTO obesity variant circuitry and adipocyte browning in humans. N Engl J Med. 2015;373(10):895-907.

106. Gachon F, Olela FF, Schaad O, Descombes P, Schibler U. The circadian PARdomain basic leucine zipper transcription factors DBP, TEF, and HLF modulate basal and inducible xenobiotic detoxification. Cell Metab. 2006; $4(1): 25-36$.

\section{Ready to submit your research? Choose BMC and benefit from:}

- fast, convenient online submission

- thorough peer review by experienced researchers in your field

- rapid publication on acceptance

- support for research data, including large and complex data types

- gold Open Access which fosters wider collaboration and increased citations

- maximum visibility for your research: over $100 \mathrm{M}$ website views per year

At BMC, research is always in progress.

Learn more biomedcentral.com/submissions 